\title{
Dose Proportionality Study
}

National Cancer Institute

\section{Source}

National Cancer Institute. Dose Proportionality Study. NCI Thesaurus. Code C158290.

A type of study designed to evaluate the relationship between dose and resulting exposure. 